Revista de la red interuniversitaria de estudios sobre las literaturas rioplatenses contemporáneas en Francia

21 | 2020

Glosolalias transplatinas: fantasmas, utopías y ficciones lingüísticas

\title{
La vida privada de los signos
}

La vie privée des signes

The Private Life of Signs

\section{Martín Arias}

\section{(2) OpenEdition}

\section{Journals}

Electronic version

URL: http://journals.openedition.org/lirico/9716

DOI: $10.4000 /$ lirico.9716

ISSN: 2262-8339

Publisher

Réseau interuniversitaire d'étude des littératures contemporaines du Río de la Plata

Electronic reference

Martín Arias, «La vida privada de los signos», Cuadernos LIRICO [En línea], 21 | 2020, Publicado el 12 julio 2020, consultado el 29 enero 2021. URL: http://journals.openedition.org/lirico/9716 ; DOI: https:// doi.org/10.4000/lirico.9716

This text was automatically generated on 29 January 2021.

\section{c) (1) $\Theta \Theta$}

Cuadernos LIRICO está distribuido bajo una Licencia Creative Commons Atribución-NoComercialSinDerivar 4.0 Internacional. 


\title{
La vida privada de los signos
}

\author{
La vie privée des signes \\ The Private Life of Signs
}

Martín Arias

\section{Coming out}

1 Hacia 1906 o 1907, Ferdinand de Saussure entusiasmó a sus alumnos con la posibilidad de "una ciencia que estudie la vida de los signos en el seno de la vida social" (43). Con el adjetivo que cerraba esa prometedora definición de la semiología, cierta escuela de pensamiento sobre el lenguaje quedaba consagrada. Según ella, si algo no puede ser jamás puesto en duda, es la intensa vida social de los signos, el hecho de que antes que a nadie, ellos pertenecen a la comunidad. Nada más evidente: los signos viven en sociedad, son animales gregarios, son públicos, son la cosa pública misma. Mi propio mensaje me viene siempre del Otro (solo a los lacanianos puede importar si bajo una forma invertida o no) y cualquier opinión en contrario roza los límites del sinsentido. Pero la vida social de los signos no siempre fue una evidencia tan incontestable, ni su negación un argumento tan escandaloso. Es más, puede hacerse una historia del coming out del lenguaje. Un válido intento en este sentido es un ensayo del epistemólogo Ian Hacking titulado “¿Cómo, por qué, cuándo y dónde se volvió público el lenguaje?”, cuyo tema, en verdad, no es lingüístico sino filosófico. Allí se lee:

¿Qué quiero decir con privado y público? Hobbes [...] escribió que el lenguaje es discurso mental. Al comienzo de sus Elementos de Filosofía, que publicó en 1656, dijo que el lenguaje tiene dos valores distintos. En primer lugar, las palabras, al ser signos de ideas, sirven como asistentes de la memoria; nos ayudan a recordar pensamientos previos. En segundo lugar, pero solo en segundo lugar, las palabras se adaptan magníficamente a la comunicación, de modo que me permiten transmitir ideas de mi mente hacia la tuya. El lenguaje es esencialmente privado y solo accidentalmente público. Descartes y Hume, Locke y Leibniz, incluso Kant, eran en buena medida de la misma opinión. Mucho después de que las ideas cedieran a los significados, algunos filósofos, como Bertrand Russell, también pensaron que los significados son tan privados como las ideas hobbesianas. "Cuando una persona usa 
una palabra, no quiere decir con ella lo mismo que otra persona quiere decir con ella" (Russell 2010: 22). (Hacking 2002: 121-122)

2 Hacking llama a los filósofos mencionados en este párrafo lingüistas privados. Aunque algunos de ellos todavía prosperaban en el siglo veinte, como muestra el ejemplo de Russell, su reinado solo se mantuvo invicto hasta el dieciocho, cuando una nueva concepción del lenguaje se abrió paso. Esto habría tenido lugar, singularmente, en la obra de Johann Georg Hamann (1730-1788), filósofo, “filólogo y verbalista”, lector fervoroso de la Biblia y buen amigo de Kant, con cuyas ideas sin embargo disentía. Kant era un lingüista privado convencido, un privatista recalcitrante ${ }^{2}$, mientras que Hamann postulaba un lenguaje esencialmente público y compartido, anterior a cualquier yo individual, pues sostenía que no hay yo individual sino en comunidades lingüísticas. Si Kant necesitaba del lenguaje para que el yo no se enfrascara en su breve cárcel solipsista, para Hamann no había necesidad de tal liberación, pues el yo está siempre ya en lo abierto del espacio público. Si avanzamos algunas décadas, veremos que el coming out parece haber sido consumado, al menos si observamos el panorama desde esa aterradora cima de Europa llamada Saber Absoluto. Hegel declara, en la Fenomenología del espíritu (1807): "El lenguaje es la autoconsciencia que es para otros" (1998: 380; las itálicas son del autor).

3 En el siglo veinte, un alumno bienamado del privatista Russell vuelve a abrir el dossier. En uno de los escurridizos parágrafos de sus escurridizas Investigaciones filosóficas, Wittgenstein expone lo que la tradición anglosajona conocerá bajo el nombre de "argumento del lenguaje privado". Lo hace con una pregunta formulada en ese tono de soliloquio desapacible que parece hecho a medida para seducir a los lectores de Thomas Bernhard:

¿Pero sería también imaginable un lenguaje en el que uno pudiera anotar o expresar sus vivencia internas - sus sentimientos, estados de ánimo, etc.- para su uso propio?- ¿Es que no podemos hacerlo en nuestro lenguaje ordinario?-Pero no es eso lo que quiero decir. Las palabras de este lenguaje deben referirse a lo que solo puede ser conocido por el hablante, a sus sensaciones inmediatas, privadas. Otro no puede, por tanto, entender este lenguaje. (1988: 219)

El exitoso "argumento", proseguido en diferentes partes de este libro, abarca cuestiones tales como "qué es ser una persona" (Hacking 136) y ha hecho correr ríos de tinta más o menos profundos. Nosotros, de las palabras citadas hace un instante quisiéramos destacar las primeras, que parecen sugerir cierta deriva hacia la ficción. Pues ¿no se trata ante todo de saber si un lenguaje es o no es imaginable ${ }^{3}$ ? La pregunta adquiere así un sesgo más bien literario. De ese sesgo o de esa deriva buscan dar cuenta las notas que siguen. En ellas no hemos pretendido evitar que la historia resumida hasta aquí se mezcle con algunas ficciones lingüísticas de la literatura argentina.

\section{Russell \& Funes}

Supongamos, entonces, que la contienda filosófica entre lingüistas públicos y lingüistas privados lleva sus hostilidades hacia las regiones propicias de la literatura. ¿Qué personajes de Borges revistan en uno $u$ otro bando? Si releemos la cita de Hacking copiada al comienzo, lo que salta a la vista es una cuestión de número: de los siete lingüistas privados que allí se mencionan, más de la mitad hace cameos filosóficos en solo dos cuentos de Ficciones. Hume, Leibniz y Russell en "Tlön, Uqbar, Orbis Tertius”, Locke en "Funes el memorioso". Esa hegemonía privatista quizá sea solo aparente, pero 
merece cierta atención, sobre todo su figura tutelar a comienzos del siglo pasado: Bertrand Russell. A Russel, el joven Borges lo definía como un autor de "libros de una lucidez inhumana, insatisfactorios e intensos" (1983: 246). Lucidez, intensidad y el exceso que sugiere la negación de lo humano: todos esos atributos están presentes en Funes. Él es tanto el "solitario y lúcido espectador de un mundo multiforme..." (490), como un "Zarathustra cimarrón y vernáculo" (485), vale decir, si no in-, al menos nietzscheanamente supra-humano. Cierto es que en el cuento el lingüista privado estrella es Locke, pero podríamos pensar que la sombra afable de Russell se proyecta sobre los comentarios del narrador acerca de la lengua que alguna vez pretendió inventar Funes.

Locke imagina un "idioma imposible en el que cada cosa individual, cada piedra, cada pájaro y cada rama tuviera nombre propio" (489). Funes había tenido la misma idea, pero acabó por reprobarla a causa de un exceso de generalidad. Para el memorioso, las "cosas individuales" de Locke son demasiado generales, ya que "no sólo recordaba cada hoja de cada árbol de cada monte, sino cada una de las veces que la había percibido o imaginado" (489). La naturaleza fugaz de su percepción impide al triste uruguayo ver en las "cosas" del filósofo inglés algo más que tosquedades metafísicas, brutalidades de las cuales, si se deriva un lenguaje, ha de ser uno igualmente brutal. Ahora bien, ¿existe un lenguaje a la altura de la exorbitante demanda de particularidad de Ireneo Funes?

7 Retrocedamos algunas páginas en Ficciones, hacia su popular primer cuento. Russell es mencionado en la segunda nota al pie, a propósito de la "hipótesis de los cinco minutos" postulada en The Analysis of Mind (1921), una serie de conferencias cuyo tema es la psicología. Borges cita la conferencia titulada "Memoria"; en la siguiente, "Palabras y significado", se lee:

En el lenguaje no hay manera directa de designar ninguno de los breves existentes últimos que forman las colecciones que llamamos cosas o personas. Si queremos hablar de tales existentes - lo cual, salvo en filosofía, raramente ocurre- tenemos que hacerlo mediante alguna frase elaborada, tal como como "la sensación visual que ocupó el centro de mi campo de visión el mediodía del primero de enero de 1919". A tales simples últimos los llamo "particulares". Los particulares podrían tener nombres propios, y sin duda los tendrían si el lenguaje hubiese sido inventado por observadores científicamente entrenados para los propósitos de la filosofía y la lógica. (1995: 161)

"Si el lenguaje hubiese sido inventado...". La fórmula condicional de Russell nos devuelve a la ficción y a las lenguas imaginables. El pasaje ofrece, por lo demás, varios puntos de contacto con "Funes el memorioso", uno de los cuales se encuentra en la idea de que las cosas o las personas son "colecciones", vale decir conjuntos (vale decir, ficciones). El famoso perro del cuento solo puede ser llamado tal si aceptamos construir un conjunto "P" hecho de cosas diferentes, tales como el perro de las tres y catorce visto de perfil y el perro de las tres y cuarto visto de frente, amén de una multitud de otros perros vistos desde otras tantas perspectivas. Además, la indicación horaria de Borges es muy cercana a la idea russelliana de que los elementos que integran tales colecciones no duran casi nada. Son brief existents, o momentary things, como leemos en otra página del mismo libro (102); y esta última expresión quizá se escuche tras una frase del cuento en que el narrador no se atreve a escribir el verbo sagrado: "creo rememorar el ascua momentánea del cigarrillo" (487). Perros inasibles, ascuas breves: el lapso de tiempo ínfimo que duran las cosas de esa colección llamada mundo no obsesiona a Russell menos que a Funes. Así, mientras el profesor inglés fecha eventos tales como "la 
sensación visual que ocupó el centro de mi campo de visión el mediodía del primero de enero de 1919", el compadrito uruguayo "sabía las formas de las nubes australes del amanecer del treinta de abril de mil ochocientos ochenta y dos" (488). La fugacidad de esas sensaciones es una exigencia de la metafísica que Russell intentaba elaborar hacia los años diez y veinte del siglo pasado, cuando escribía esos libros tan insatisfactorios e intensos que con fervor leía Borges. En 1918, en una conferencia dictada en Londres, Russell decía:

En cuanto a los datos sensibles pasajeros [fleeting sense-data], creo que es muy importante que eliminemos de nuestros instintos toda disposición a creer que lo real es lo permanente. Siempre ha habido un prejuicio metafísico en el sentido de que si una cosa es realmente real, tiene que durar para siempre, o bien por un periodo de tiempo bastante decente. En mi opinión, eso es un completo error. Las cosas que son realmente reales duran un tiempo muy corto. De nuevo, no estoy negando que pueda haber cosas que duren para siempre o mil años; solo digo que esas cosas no están dentro de nuestra experiencia, y que las cosas reales que conocemos a través de la experiencia duran un tiempo muy corto, una décima de segundo o medio segundo o lo que sea. [...] Las cosas que llamamos reales, como las mesas y las sillas, son sistemas, series de clases de particulares, y los particulares son las cosas reales, al ser los datos sensibles cuando estos nos son dados. Una mesa o una silla son series de clases de particulares, y por tanto una ficción lógica. (2010: 116)

9 Ficciones como las mesas, las sillas o los perros (o los números, que para Russell son conjuntos de conjuntos y por tanto ficciones de ficciones ${ }^{4}$ ) no forman parte de nuestra experiencia, reino de datos sensibles y de pura fugacidad, sino solo de nuestro lenguaje. En este punto pasamos al registro condicional de las lenguas imaginables. Pues si para esa filosofía que reconoce en Russell a uno de sus padres fundadores (la analítica) el problema central es "cómo las palabras se enganchan al mundo" (Putnam 43), el lenguaje cotidiano (o aun, en el límite enloquecedor de Funes, el lenguaje imposible postulado por Locke) carece de todo punto de enganche, al confundir el mundo con un amontonamiento de colecciones ficcionales. El anzuelo del lenguaje atraviesa esos peces fantasmas para volver, vacío, al desencantado pescador. Dada esta naturaleza espectral de las palabras, si queremos evitar que las inferencias falaces del lenguaje cotidiano nos conduzcan a hacer inferencias falaces sobre el mundo, necesitamos postular otro lenguaje: un anzuelo perfecto. En tal lenguaje,

habría una palabra, y no más, para cada objeto simple, y todo aquello que no fuera simple se expresaría por medio de una combinación de palabras correspondientes a las cosas simples - una palabra por componente- que formen parte de dicho complejo. Un lenguaje de este tipo sería completamente analítico, y mostraría a simple vista la estructura lógica de los hechos afirmados o negados. El lenguaje descrito en los Principia Mathematica es un lenguaje de este tipo. Es un lenguaje que solo tiene sintaxis, y ningún vocabulario en absoluto. Exceptuando la omisión de un vocabulario, sostengo que es un lenguaje bastante bonito. Apunta a ser el tipo de lenguaje que, si se le añade un vocabulario, sería un lenguaje lógicamente perfecto. Los lenguajes existentes no son lógicamente perfectos en este sentido, ni tendrán nunca posibilidad de serlo si han de servir para los propósitos de la vida cotidiana. Un lenguaje lógicamente perfecto, si pudiese ser construido, sería no solo intolerablemente prolijo, sino además, en lo que concierne a su vocabulario, en una medida muy grande exclusivo de un hablante [private to one speaker]. Es decir, todos los nombres que emplearía sería exclusivos [private] de ese hablante y no podrían entrar en el lenguaje de otro hablante. (2010: 25-26) 
Las "cosas simples" de este párrafo no son, de nuevo, las brutales piedras de Locke, sino los fugaces datos sensibles de Funes. No son los pájaros del filósofo inglés del siglo XVII; son los "perros" (en verdad, los "particulares" agrupados o ficcionalizados más tarde en el conjunto "P") del memorioso uruguayo. En un lenguaje lógicamente perfecto, esos "particulares" serían designados por "nombres propios", pero no como los que usamos habitualmente, pues esos están "infectados de vaguedad" (Russell 2010: 144), sino por otros que mantienen con lo designado, con esos existentes instantáneos de menos de un segundo, una relación uno a uno. Esto nos conduce al mundo privado ${ }^{5}$. Pues aquello que designan tales nombres propios no es otra cosa que datos sensibles, y estos siempre se presentan a alguien, a un "espectador" determinado (como se lee en The Analysis of Mind), son algo de lo que ese espectador tiene cierto conocimiento (cierta acquaintance). Ello no sería un problema si pudiésemos usar ese mismo nombre propio para designar la acquaintance del otro, el dato sensible dado a otro espectador y así comunicarnos, pero la relación uno a uno nos impide ese recurso usual al malentendido. El nombre propio lógico de mi dato sensible es tan inajenable como el Aleph de Carlos Argentino. El lenguaje lógicamente perfecto de Russell se hunde así en las cuevas de la privacidad. Allí encontramos esa deliciosa miniatura surrealista, ese surrealismo sin Breton que es el sistema numérico inventado por Funes, cuyos términos son El Negro Timoteo o manta de carne. Entonces, la frase de Russell: "los particulares podrían tener nombres propios, y sin duda los tendrían si el lenguaje hubiese sido inventado por observadores científicamente entrenados para los propósitos de la filosofía y la lógica” puede reformularse con las palabras del cuento: “...si el lenguaje hubiese sido inventado por lúcidos espectadores de un mundo multiforme, instantáneo y casi intolerablemente preciso". o bien, brevemente: "si hubiese sido inventado por Funes". Que el memorioso no sea "muy capaz de pensar" no basta para impugnar su eficacia como observador entrenado para la filosofía, al menos si tenemos en cuenta las refutaciones de conceptos abstractos del tipo "significado", "creencia", "pensamiento", esgrimidas por filósofos como Quine (Hylton y Kemp $2020 \mathrm{Web})^{6}$. También puede verse del modo inverso: Funes es el filósofo absoluto, alguien apto para entender el mundo en toda su pluralidad -un mundo "supernominalista", como lo describe Dapía (39)-, solo que carece de un lenguaje adecuado para comunicar sus descubrimientos. Toda "comunicación" se convierte aquí en eso que, a propósito del sistema numérico, el narrador borgeano llama una "rapsodia de voces inconexas" (489), una verdadera glosolalia.

\section{Más lingüistas privados}

11 De este modo, volvemos a la descripción propuesta por Hacking: Russell como "lingüista privado". Descripción tanto más plausible por cuanto, en The Analysis of Mind, el libro citado en la segunda nota de "Tlön, Uqbar, Orbis Tertius", leemos esta declaración de principios:

La esencia del lenguaje no se encuentra en el uso de tal o cual medio especial de comunicación, sino en el empleo de asociaciones fijas (como sea que estas se hayan originado) a fin de que algo ahora sensible - una palabra dicha, una imagen, un gesto, o lo que sea- evoquen la "idea" de algo más. Cuando esto se da, lo que es ahora sensible puede ser llamado "signo" o "símbolo", y aquello de lo que pretende evocar la "idea" puede ser llamado su "significado". Este es un tosco esquema de lo que constituye el "significado". Pero debemos rellenar el esquema de diversas maneras. Y, puesto que nos interesa lo que se llama "pensamiento", debemos 
prestar más atención de lo acostumbrado al uso privado del lenguaje, por oposición a su uso social. El lenguaje afecta profundamente nuestros pensamientos, y este aspecto del lenguaje es de la mayor importancia para nosotros en esta investigación. Casi nos importa más el discurso interno que nunca se pronuncia que las cosas dichas en voz alta a otra gente. (159-160)

Quizá no sea superfluo aclarar que esta referencia a un "uso privado del leguaje" aparece en un libro cuyo tema es la psicología; en tal sentido, y a pesar de que se trate de palabras casi idénticas, no debería confundirse con el "lenguaje privado" al que aludimos más arriba, ligado más bien a consideraciones de orden metafísico (es este último, seguramente, el que inspiró a Wittgenstein su aclamado "argumento") ${ }^{7}$. Bien podemos estar aquí en presencia de un lenguaje perfectamente público del que, sin embargo, se hace un uso íntimo, aunque sería exagerado suponer que ambos están por completo desconectados. En cualquier caso, el hecho de que Borges tuviera presente este libro de Russell mientras escribía uno de sus relatos canónicos merece más de una consideración ${ }^{8}$. Pues ese "discurso interno" y nunca proferido, ese uso privado del lenguaje que sería más esencial que todo lo dicho ¿no está en el centro de la ficción de Borges? o para limitar la generalidad del argumento, ¿no está en el centro de esa zona de la ficción de Borges que protagonizan "lingüistas privados" tales como Juan Dahlmann, el mago Tzinacán, Jaromir Hladík o, si consideramos también la poesía, Isidoro Acevedo? Aunque, a diferencia de Funes - un lingüista privado en sentido lógico estricto-, estos sean lingüistas privados en sentido más bien psicológico, no por ello pertenecen menos al bando privatista. Todos ellos nos conducen a un espacio literario en que los lectores somos afectados "más por el discurso interno que nunca se profiere que por las cosas dichas en voz alta a otras personas" (Russell). Así, en "La escritura del dios", Tzinacán nunca profiere la divina sentencia; toda la peripecia de lectura y desciframiento tiene lugar en su mente, encerrada en un cuerpo encerrado. En "Las ruinas circulares", la fábula entera es un discurso interno, un sueño soñado por un gran Otro desconocido. En "El Sur", según la lectura sugerida por el narrador, no bien Dahlmann aborda el coche de plaza que lo llevará a Constitución, entramos en su espacio mental y en el sueño de su muerte elegida. Isidoro Acevedo, en el poema del mismo nombre, reúne rasgos privatistas de Dalhmann y de Funes; sueña su muerte $y$, para hacerlo, recurre a su memoria: "congregó los archivos de su memoria / para fraguar su sueño"; Isidoro, igual que Ireneo, muere de una "congestión pulmonar" (86). El milagro que Dios concede a Jaromir Hladík es el de un uso íntimo del lenguaje. En todos estos casos asistimos a aventuras privadas, a "discursos internos", jamás revelados a otras personas salvo por la dicción - tan paradójica como la figura divinade la voz narrativa. Una observación en el mismo sentido: una de las lenguas inventadas que encontramos en "Tlön, Uqbar, Orbis Tertius", la empleada para traducir la frase tlöniana "hlör u fang axaxaxas mlö", es decir, la frase atribuida a Xul Solar "upa tras perfluye lunó", es a todas luces el neocriollo, cuyo uso primordial ha sido el de registrar, en el diario espiritual titulado San Signos, una experiencia tan privada como una visión mística (en esto, Xul se parece a Tzinacán). -Otra observación sobre la lengua tlöniana (y el sueño): quien tenga presente que Borges era un lector de Lovecraft, quizá no encuentre descabellado asociar la lengua imaginaria de Tlön con la lengua imaginaria de la ciudad espantosa de R'lyeh, en The Call of Cthulhu (1928), y la palabra tlöniana fang con la palabra r'lyehana fhtagn, presente en la frase "Cthulhu fhtagn", escuchada, por cierto, en un sueño-. 
Por supuesto, la literatura ha fabricado innumerables dispositivos capaces de entrar tanto en la mente de los personajes como en sus mundos privados, superando la queja emitida por Tristram Shandy ante la imposibilidad de ver la mente de su tío Toby: "nuestras mentes no resplandecen a través del cuerpo, sino que están envueltas en un oscuro ropaje de carne y sangre sin cristalizar" (Sterne $2006 \mathrm{Web}$ ). En el dispositivo borgeano, sin embargo, el lenguaje (o su uso) privado no es solo una decisión narrativa, sino la condición misma de la fábula, lo que radicaliza la opacidad de los personajes -su carne y sangre sin cristalizar- hasta volverla fulgurante.

\section{Una mujer publicada}

14 Ahora bien, podríamos pensar que frente a los lingüistas privados borgeanos, mártires introspectivos, surge una facción adversa, peligrosa, pública. Emma Zunz y James Alexander Nolan podrían ser sus héroes. Ellos reintroducen cierta dimensión moral o política que el lenguaje lógicamente perfecto, al impedir la ambigüedad y cancelar al Otro, había bloqueado por completo. En este nuevo espacio abierto, es necesario que las palabras (según la metáfora de Russell acerca del lenguaje cotidiano) estén "infectadas de vaguedad”. A diferencia de los privados, los lingüistas públicos aceptan el desenganche irrecuperable entre lenguaje y mundo, se entregan al ambiguo doble juego con que los signos se entretienen en su vida social, y así pasan al reino político de la equivocidad. El acto con que Emma lleva a cabo su venganza consuma, a un tiempo, el paso a la esfera pública (levantar el teléfono para comunicar el homicidio a las autoridades) y al terreno incierto y vago de la publicidad lingüística, donde los nombres que designan cuerpos, sentimientos, actos y lugares pueden migrar de una cosa a la otra, faltando a la verdad solo para servir a la justicia. La historia de Emma es la de ese salto a lo público. Es por ello que el narrador nos dice: "Acaso en el infame Paseo de Julio se vio multiplicada en espejos, publicada por luces y desnudada por los ojos hambrientos..." (565). Esta cita encubre un aspecto de la "lingüística pública" borgeana que nos interesará en un momento: lo obsceno. Ciertamente, la ambigüedad es una infección del lenguaje cotidiano. Por eso Jaime Rest subrayaba, a propósito de "Emma Zunz", la "ambigüedad que es inherente a cualquier signo, ya que toda operación semántica entraña inevitablemente un resultado que es escurridizo en mayor o menor grado" (116). Habría que añadir que en este cuento, la ambigüedad se aproxima a la sicalipsis, al doble sentido sexual (mujer publicada/mujer pública, "una mujer de todos" (127), como se lee en Evaristo Carriego), incluso al doble sentido de los chistes obscenos, algo menos presente en el encuentro con el marinero que en el trayecto público de Emma. Este incluye, como se recordará, la visita con una amiga a la pileta de un club de mujeres: "Se inscribieron; tuvo que repetir y deletrear su nombre y su apellido, tuvo que festejar las bromas vulgares que comentan la revisación" (565). A la inscripción del nombre en el espacio público le corresponde una doble inscripción (un doble sentido ambiguo) en el registro maligno de lo obsceno.

También la trama de "Tema del traidor y del héroe" se sustenta en un desfase entre lenguaje público y mundo. Este cuento, vale la pena recordarlo, si bien se abre con la invocación al "consejero áulico Leibniz" - un privatista-, incluye una mención a Hegel, a quien Ian Hacking ubica entre los lingüistas públicos ${ }^{9}$. También aquí se trata de hacer pasar una conexión mental ("Nolan concibió un extraño proyecto" (498)) hacia la esfera pública; en este sentido, el "proyecto" de Nolan equivale al "plan que había tramado" 
Emma (565). Si la mente de Nolan enlaza dos series, la serie de la historia de Irlanda y la serie literaria (Shakespeare), y aplica los nombres de una a los actos de la otra, es porque funciona siempre ya en el espacio público, cuya atmósfera (cuya "semiósfera", diría Lotman) contiene suficientes dosis de vaguedad como para que Fergus Kilpatrick asuma en la historia y la política un destino trazado en la ficción. $\mathrm{Si}$, en términos de Hegel, podría decirse que actúa aquí la astucia de la razón, la cual vuelve universal (histórico) aquello que se mostraba como la baja pasión individual y privada de un traidor, hay que añadir que lo hace sirviéndose de la vaguedad del lenguaje. -Es de notar que Hegel (1965: 129) ejemplifica la famosa "astucia" con la figura de Julio César, y que Julio César es una de las dos obras de Shakespeare de que se sirve Nolan-. En el cuento, el delicado juego entre lo privado y lo público se sostiene hasta el desenlace, cuando Ryan, que ha descubierto la secreta trama político-literaria, decide (igual que Tzinacán con la sentencia escrita en el jaguar) mantener esa revelación en la esfera privada de su mente y, como se lee en la última línea, "Publica[r] un libro dedicado a la gloria del héroe" (498; las itálicas son nuestras). Así, el lenguaje de lo público atraviesa todo el relato, en el cual la posición final y por tanto estratégica del verbo "publicar" confiere a este un lugar tan notorio como el que, en "Emma Zunz", ocupa la sorprendente metáfora de la "mujer publicada".

Pero si de lingüistas públicos en Borges (y Bioy) se trata, podría sostenerse que el más radical de todos ellos es $\mathrm{H}$. Bustos Domecq, autor de esa pieza de tema tan abiertamente político que es "La fiesta del monstruo" (1947). No puede extrañar, entonces, que la lengua del cuentista de Pujato, siendo la más pública de todas y la más política, sea también la más enrarecida, la más enloquecida o (copiemos la puntuación de Nicolás Rosa) la más a-locada: fuera de razón y fuera de lugar. Hay una palabra que la lengua alocada de Bustos Domecq es incapaz de pronunciar, y es precisamente el nombre público por excelencia. En lugar de "Perón", el texto dice "monstruo". El más público de los nombres propios argentinos, ese que hacia 1947 estaba en boca de todos, se infecta con una substancia obscena que lo vuelve indecible, insufrible, impresentable. Borges (en francés) lo dijo claramente: "es casi una palabra obscena, que no nos gusta decir. Buscamos eufemismos" (Prat y Dumayet 1964). ¿Qué es la lengua de "La fiesta del monstruo" sino una acreción verbal alucinatoria en torno a la falta de un nombre obsceno? Esto es bien sabido, pero conviene tenerlo en cuenta como punto de enlace hacia otras lenguas imaginables.

\section{Cosmopolitismo y tabú: historia de la lengua ${ }^{10}$}

Si se admite (siguiendo el discurso de la Universidad) que la lengua es un corpus, se admitirá también que toda extirpación practicada en ese cuerpo ha de dejar una marca, una cicatriz más o menos profunda, más o menos perceptible. A lo cual conviene agregar que una cicatriz, como cualquier línea sobre una superficie, tiene la virtud de conectar puntos diversos. En el corpus de la lengua argentina, la marca dejada por la expulsión del nombre público ha suscitado todo tipo de conexiones. Van desde, digamos, la política y la literatura hasta la lexicografía, la jurisprudencia, la historiografía y la toponimia. A partir de ellas podría desplegarse un considerable muestrario, pero mejor es atenerse a algunos elementos cruciales. Se verá entonces hasta qué punto el juego de inclusiones y exclusiones de nombres públicos involucra a la ficción lingüística. 

público ("La fiesta del monstruo" se publica en Montevideo en 1955, aunque circulaba desde 1947), el gobierno golpista prohibía formalmente el uso de "Nombres que Lesionaban la Democracia Argentina". Entre ellos están "el nombre propio del presidente depuesto, el de sus parientes, las expresiones 'peronismo', 'peronista', 'justicialismo', 'justicialista', [...] la abreviatura PP, las fechas exaltadas por el régimen depuesto...” (B. O. de la República Argentina). Esa sustracción de nombres respondía, como contragolpe, a los intentos de inclusión lexicográfica del gobierno peronista, cuyos agentes habían bregado para que la Real Academia Española agregase a su Diccionario ciertas palabras caras al movimiento. Todavía en 1958, los funcionarios del gobierno de Aramburu se deleitaban con el fracaso de aquellos intentos, como lo muestra un folleto de Vicepresidencia de la Nación delicadamente titulado "Libro negro de la segunda tiranía" (publicado también en virtud de un decreto):

Uno de los más nefastos ministros de la dictadura, Armando Méndez San Martín, [...] [p]idió [a la Academia Argentina de Letras] que solicitara y prohijara la aceptación de la palabra "justicialismo" por la Academia Española. Estudiada la proposición, la academia la rechazó por buenas razones lingüísticas. (Glozman 2015: 350)

Ese juego de exclusiones de nombres públicos, que duraba ya años, era también un juego de inclusiones. En 1953, todavía durante la fase peronista, el Ministro de Asuntos Técnicos de Perón había declarado ante una asamblea:

La lengua es fundamental para la integración de la cultura nacional. ¿Qué se entiende por esto? No es que pretendamos crear o tener un idioma argentino pero sí no depender de nadie en materia idiomática. Existen en nuestro país y en nuestro pueblo palabras nuevas, nuestras, que no figuran en los diccionarios que nosotros consideramos como oficiales de nuestra lengua. La palabra "Justicialismo", por ejemplo, definida y expuesta por primera vez por el general Perón el $1^{\circ}$ de mayo de 1947 en este mismo recinto, que importa toda una definición de una nueva cultura en el mundo, no ha sido todavía incorporada al Diccionario de la Real Academia Española. (97)

Una tragicomedia lingüística: en uno sus actos se pretende borrar de la faz de la tierra, por decreto, una serie de palabras y hasta de iniciales de palabras; en el otro se reivindica la independencia idiomática luchando con innegable patriotismo para que la Real Academia Española acepte incluir en su repertorio, que "nosotros consideramos oficial", las palabras "nuevas, nuestras". ¿No deriva de ahí, de esa trágica comedia de enredos léxicos, esa lengua ficcional de la literatura argentina llamada comarquí? Hablamos del idioma inventado por Osvaldo Lamborghini en su novela Tadeys. De todas las palabras de ese idioma ficcional, quizá la más importante sea tadey, cuyo significado original es "visión". El tadey es un animalito erotizado cuya carne (comestible, deliciosa) es la base de la riqueza del país, a punto tal que la moneda nacional se llama tadey argenta. Nada hay más público en La Comarca que la palabra tadey o que su variante tadeo. Ella circula entre todos, como es natural. Y sin embargo, la palabra no figura en el Diccionario Oficial. Leamos este fragmento en que el pusilánime Ministro de Educación y Cultura del país se dirige al terrible Jones Hien, "hombre de intrigas tan enormes como sus zarpas":

- Hace dos años estoy al frente del ministerio, y puedo jurar que para mí la inclusión en el Diccionario de la Lengua de la palabra tadeo es un sueño que me persigue desde la infancia, y no me avergüenzo por otra parte: provengo de una familia dedicada exclusivamente a los tadeys, pero en cuanto a la introducción del término... 
- ¿Tadeys?- preguntó malévolamente Jones Hien.

-Tadeys o tadeos, pero que aparezca en el Diccionario oficial -agobiado (se escuchaban algunas risas), como si estuviera a punto de caerse de su escaño, repuso el ministro. Y agregó: -Son los académicos quienes toman estas decisiones. Todo lo probé para que voten positivamente, hasta propuse la voz tadeus que podría hacer pensar en una etimología latina. Pero se han negado por completo. Pretenden que es de tan mal gusto en cualquiera de sus variantes como si en el Diccionario Oficial incluyéramos puto además de sodomita. En fin: ni tadeo ni tadeys. Y tampoco tadeus. (Lamborghini 2005: 69-70)

21 Este ansioso ministro no solo replica en la ficción las disputas idiomáticas en torno al peronismo; también reactiva, teatralizándolos sobre el fondo alucinante del imperio imaginario, mecanismos muy profundos del cambio lingüístico, tales como el préstamo a otra lengua (en este caso, el latín) para remplazar una palabra que, por alguna razón, produce espanto. Como explica el historiador de la lengua Ralph Penny: "Puede comprobarse que los préstamos extranjeros sirven igual que los eufemismos para proporcionar sustitutos a las palabras tabú" (1993: 332). Así, en castellano, “izquierdo", cuyo concepto se asocia a lo ominoso, a lo diabólico, al mal, no proviene del latín, como la mayor parte de las palabras castellanas, sino del vasco (ezkerra). El horror ante aquello a lo que de manera abierta, transparente, intensa, alude una palabra que nos es demasiado cercana, impone el uso de un sustituto foráneo, el velo cosmopolita de una "barrera idiomática". Si la literatura de Osvaldo Lamborghini sigue siendo intolerable, es porque él escribe siempre en ese nivel enterrado (arqueológico) en que el espanto (la historia) actúa sobre el lenguaje y deja allí vestigios, marcas, máscaras. Como Funes, Lamborghini ignora el latín, pero igual interviene directamente en lo arcaico de la lengua. De hecho, podríamos avanzar la hipótesis de que el idioma imaginario de Tadeys radicaliza el mecanismo diacrónico del préstamo por tabú, y de ahí su asombrosa mezcla lingüística:

El enredo lingüístico de LacOmar, inextricable derivado de una mezcla de raíces latinas, eslavas y arábigas, complicaba aún más el problema político y religioso... (178)

...el enredo lingüístico de La Comarca -mezcla inextricable de raíces latinas, eslavas y hebreas... (347)

El problema político y religioso se enredaba aún más por las complicaciones lingüísticas de La Comarca, inextricable trabazón, su lengua, de raíces latinas, eslavas, hebreas e incluso (inexplicablemente) vascas, como se llegó a afirmar, y no sin autoridad. (320)

Podríamos atribuir esta formidable complicación etimológica al mecanismo indicado R. Penny, quien menciona tres tabúes activos en castellano: el tabú del miedo, el tabú de la delicadeza, el tabú de la decencia (331-333). Lamborghini infringe todos, pero quizás el comarquí, a diferencia de lo que podría suponerse y de lo que afirma el mismo narrador ${ }^{11}$, sea una lengua de un pudor superlativo, una suerte de langage précieux disfrazado de obscenidad. Es lo que el narrador-lingüista de Tadeys llama "lo vergonzante: “...La Comarca vivía abrumada aún por su pasado, no tan remoto: un siglo atrás creían que la crianza y la industrialización del tadeo (o tadey: hasta la falta de una ortografía precisa indica cierta actitud vergonzante..." (69). La pudibundez ante lo "vergonzante" impone que el idioma comarquí, frente a la mínima posibilidad de faltar al decoro, de rozar siquiera alguno de los tres tabúes, recurra a otra lengua y así se disperse en étimos, en préstamos, en arborescencias inusitadas. En este sentido (la acechanza ominosa del tabú), se diferencia de la mezcla de orígenes más bien festiva que muestra el neocriollo de Xul, idioma con el que sin embargo tiene puntos en 
común, empezando por el sentido de la palabra tadey, que designa en comarquí la función misma del neocriollo en San Signos: registrar por escrito "visiones" místicas ${ }^{12}$.

Podríamos suponer también que el paso a otra lengua como reacción ante alguno de los tres tabúes, o a los tres al mismo tiempo, se reconoce en el título de uno de los "Borradores y reescrituras" de Tadeys - "Tadeys o muerte"- , donde, antes que la antinomia Patria o muerte, leemos aquella otra, escrita en lo más profundo de la Argentina: Perón o muerte, consigna de la izquierda peronista y apropiado título del libro de Verón y Sigal sobre "los fundamentos discursivos del fenómeno peronista" (1985). De nuevo, el nombre público argentino es puesto fuera de lugar; es un nombre atópico, a-locado. Si puede escucharse aquí una réplica a Borges-Bioy (el "monstruo" es remplazado por el tadey), el tabú que activa el recurso a la palabra extranjera, proveniente esta vez de una lengua imaginaria, podría ser muy otro, corresponder a otro miedo, a otra delicadeza. Pues para Lamborghini, decir Perón era decir El fiord (era decir: "la sonrisa ortopédica del viejo Perón"), era decir el origen de la literatura, los años sesenta del siglo pasado. En aquel entonces, El fiord podía ser leído. Germán García, Oscar Masotta lo hicieron. Pero Tadeys no pertenece a los sesenta. Tampoco a los setenta. Como el Teatro Proletario de Cámara, esta novela disipa ese adorable espejismo: el "escritor de los años setenta". Se escribe en 1983. Se publica en España (Del Serbal) recién en 1994. En Argentina (Sudamericana), habrá que esperar hasta 2005. Esa demora entre escritura y publicación, más que una peripecia editorial, es la señal de que se trata del libro de un nuevo siglo. Imposible abreviar la espera. Hasta conviene desconfiar de que haya terminado. De que hoy podamos sin escándalo asistir a una adaptación teatral de Tadeys en el centro de Buenos Aires no se sigue que estemos en condiciones de leer la novela ${ }^{13}$.

Primero habría que entender su lengua. Palabras como toíve, taddís o lindom, y conocer su historia. Pues la lingüística en La Comarca es esencialmente diacrónica. Esto no solo se debe a su naturaleza novelesca, sino también al hecho de que en su exasperada lengua las palabras no logran deshacerse nunca de su origen:

Hasta el día de la firma del solemne acuerdo, en latín, el término lindom significaba barón o hidalgo (no hay traducción exacta), pero fue tal la masacre y persecución de lindoms, esa misma noche desatada en todo el país, que el significado de la palabra se transformó en algo semejante a "bandolero, criminal, fugitivo de la justicia". (205)

Todo el libro puede ser recorrido como la descripción de transformaciones semánticas como esta. Si John Wilkins sueña con una lengua sin secretos, una lengua que descubre de un vistazo la taxonomía del universo; si Russell postula una lengua que muestra "a simple vista la estructura lógica de los hechos afirmados o negados", Lamborghini imagina una lengua que exhibe su historia. Conviene aclarar, de inmediato, que dos definiciones de "historia" actúan aquí al mismo tiempo, en conflicto. Según una de ellas, "todavía hoy, lo que nuestros niños aprenden en la escuela como historia universal es, en lo esencial, una seguidilla de matanzas de pueblos" (Freud 1992: 293); según la otra: "Quizá la historia universal es la historia de la diversa entonación de algunas metáforas" (Borges 1983: 638). Casi podría decirse, a riesgo de cometer un "abuso de lenguaje": el lenguaje de un autor, con su personal "entonación", y el lenguaje público de la guerra. No es que las dos acepciones alcancen una síntesis en Tadeys. Más bien actúan como una doble exigencia o una doble sujeción impuesta a quien emprenda su lectura. 


\section{Gruñidos y chillidos} idioma analítico, nosotros quisiéramos conservar un solo detalle. Son las palabras finales, de Chesterton, que importan por dos razones. La primera es que son "acaso lo más lúcido que sobre el lenguaje se ha escrito"; la segunda es que nos conducen a las lenguas inventadas por Osvaldo Lamborghini:

Esperanzas y utopías aparte acaso lo más lúcido que sobre el lenguaje se ha escrito son estas palabras de Chesterton: "El hombre sabe que hay en el alma tintes más desconcertantes, más innumerables y más anónimos que los colores de una selva otoñal. Cree, sin embargo, que esos tintes, en todas sus fusiones y conversiones, son representables con precisión por un mecanismo arbitrario de gruñidos y de chillidos. Cree que del interior de un bolsista salen realmente ruidos que significan todos los misterios de la memoria y todas las agonías del anhelo". (Borges 1983: 709) squeals del texto original son traducidos por "gruñidos" y "chillidos" - es la siguiente: el narrador de Tadeys se sirve de las mismas palabras para describir el "lenguaje" 14 con que se comunican los apasionados mamíferos de la especie tadey: "chillidos gruñidos" (195), "gruñir o chillar" (220), "gru-ñochillidos" o "gruñochillidos" (234). La coincidencia no se da en el vacío. En la escritura de Lamborghini, abarrotada con las incrustaciones memoriales de las literaturas leídas (una poética de lo inolvidable), acecha Borges. Acechan, en Tadeys, "El 'Biathanatos", "Las ruinas circulares", "Un teólogo en la muerte" y el reservorio de lenguas imaginadas "Tlön, Uqbar, Orbis Tertius", con todas sus inflexiones neocriollas ${ }^{15}$. Hay además otro indicio, acaso más atendible que la mera coincidencia léxica y el conjunto de alusiones: "El idioma analítico de John Wilkins" es el único texto de Borges mencionado en los Escritos de Lacan. Allí, nada menos que en el seminario sobre "La carta robada", se habla de "la utopía semiológica del obispo Wilkins", y en nota al pie se aclara: "La misma a la que el señor Jorge Luis Borges, en su obra tan armónica con el phylum de nuestro discurso, concede un honor que otros reducen a sus justas proporciones" (17). No es el tipo de dato que un escritor de Literal se hubiese permitido pasar por alto: Lacan solo nombra a Borges a propósito de una lengua imaginaria. Todavía más, lo nombra a propósito de una palabra inventada por Wilkins, nullibiety, que designa el "ningún lugar", el no-lugar de la carta robada, la utopía de la letra (ver Brient 2007).

Pero antes que la voz algo bufonesca de Lacan, quien tenga a bien aguzar el oído escuchará, en los gruñidos y chillidos de los tadeys, la voz católica de Chesterton, lo que sin duda honra a ese desventurado discípulo del Padre Brown: el monje Maker. Nosotros quisiéramos notar que el texto de Chesterton del que Borges entresaca el pasaje participa de las ideas clásicas atribuidas por Ian Hacking a los lingüistas privados ${ }^{16}$. Se habla allí, en efecto, de "estados de ánimo y significados internos" ("internal moods and meanings") y de un "interior" ("his own inside") del cual brotan hacia el espacio público, representado por la figura del agente de bolsa, puros ruidos, así como Russell nos habla de un "discurso interno" y, a propósito del lenguaje cotidiano que habilita la comunicación, de unos "ruidos sin sentido" (Russell 2010: 13) -al leer a Russell, se tiene por momentos la impresión de que, a no ser por la lógica simbólica, todo el lenguaje se confundiría con una glosolalia absoluta-. La diferencia es que Chesterton degrada esas inanidades sonoras al plano de lo animal. El paso desde el mundo privado hacia la esfera pública, en lugar de consumar la integración del 
lenguaje a la vida social de los signos, lo rebaja a una práctica indecorosa, sucia y hasta bestial. Algo apto para, digamos, los manejos novelescos de Osvaldo Lamborghini. Si los chillidos y los gruñidos de los tadeys forman un sistema de signos, queda claro que solo un lingüista público podría estudiarlos. Desesperadamente, los tadeys son seres públicos. En la novela, la primera vez que se nos presenta uno lo encontramos exhibido en una jaula, como show pornográfico ante los ojos fascinados de los espectadores (133); más adelante, hacia el final de la historia de Maker, el Gran Tadey y el cura traductor se acoplan frente a una contemplativa "masa animal" (216), una "greytadey", casi una congregación. Una multitud atenta y demasiado humana. Que lo obsceno y lo público se vuelvan indiscernibles nos dice menos sobre la herencia "setentista" de Lamborghini - lo mismo ocurría con el cuerpo pornográfico de "la obrera Zunz" en el infame Paseo de Julio ${ }^{17}$ - que sobre las capas más hundidas de la lengua argentina ${ }^{18}$.

***

Solo un lingüista público, entonces, podría estudiar el idioma inenarrable de los tadeys. ¿Hamann? ¿Hegel? Quizá su divulgador Alexandre Kojève, traducido en Buenos Aires por Juan José Sebreli y leído, según el testimonio de su albacea literario, por Osvaldo Lamborghini. Como es bien sabido, Kojève sostenía la tesis de que la historia, entendida como el despliegue de la negatividad humana, como la negación por el Hombre de lo dado, de lo natural (de lo animal), tenía un final, un límite luego del cual se iniciaba un periodo post-histórico, peligrosa idea que supo alimentar cierto pensamiento antiprogresista. Quizá una frase del borrador "Tadeys o muerte" recoja alguna discusión política al respecto (acaso el sujeto de esta frase sea Kojève: "niega la Historia, es un reaccionario" (358)). Un pasaje del texto traducido por Sebreli nos muestra a este filósofo describiendo, no solo la época post-histórica -en la cual el humano, desactivada ya la máquina antropogenética de la negatividad, se vuelve animal- sino además su lenguaje:

Si el Hombre vuelve a devenir animal, sus artes, sus amores y sus juegos deben también devenir puramente "naturales". Por tanto habría que admitir que, después del final de la Historia, los Hombres construirían sus edificios y sus obras de arte como los pájaros construyen sus nidos, las arañas tejen sus telas, ejecutarían conciertos musicales a la manera de las ranas y las cigarras, jugarían como juegan los cachorros y se entregarían al amor como las bestias adultas. [...] Pero hay más. "El aniquilamiento definitivo del Hombre propiamente dicho" significa también la desaparición definitiva del Discurso (Logos) humano en el sentido estricto. Los animales de la especie Homo sapiens reaccionarán por reflejos condicionados a señales sonoras o mímicas, y sus llamados "discursos" serán así semejantes al pretendido "lenguaje" de las abejas. (Kojève 1972: 241)

Es sabido que Georges Bataille reprochaba a Kojève el tono burlesco con que este se refería a la condición post-histórica. Lamborghini, en Argentina, bien pudo haber apreciado esas entonaciones de comedia, aun en la versión de Sebreli. Este traduce, en la última línea citada, réagiraient por "reaccionarán" y seraient por "serán", convirtiendo en un futuro bastante asertivo lo que en el texto francés no era sino condicional. El detalle cuenta, no solo porque el condicional expresa la actitud desapegada y un tanto exasperante de Kojève, sino además porque es el tiempo con que la prosa de los pensadores inicia, en torno al lenguaje, sus derivas ficcionales. De ellas toma nota la literatura. Esto también puede decirse con las palabras de otro pensador: Las lenguas imaginadas por los filósofos del pasado oprimen como una pesadilla el cerebro de los escritores ${ }^{19}$. 


\section{BIBLIOGRAPHY}

Arias, Martín, “El Concilio: notas sobre las ‘sagradas letras’ en Trento de Leónidas Lamborghini y otras novelas argentinas", Revista iberoamericana (Vol. LXXXIV), $\mathrm{N}^{\circ} 263$, Pittsburgh, University of Pittsburgh, abril-junio de 2018, p. 469-483.

---, “Gramáticas de la exasperación”, en Bush, Matthew y Castañeda, Luis, Un asombro renovado. Vanguardias contemporáneas en América Latina, Madrid, 2017, Iberoamericana-Vervuert, p. 101-126.

---, “Un autor licencioso: pornografía y lenguaje en el Teatro proletario de cámara de Osvaldo Lamborghini”, Iberic@l. Revue d'études ibériques et ibéro-américaines, $\mathrm{n}^{\circ} 7$, París, Université Paris IV Sorbonne, primavera de 2015, p. 11-27.

---, “Una novela de Oriente: Tadeys y la ficción despótica”, en López, Silvana (coord.), Héctor Libertella / Osvaldo Lamborghini: la escritura-límite, Buenos Aires, Corregidor, 2016, p. 125-149.

Blanco, Mercedes, “Arqueologías de Tlön. Borges y el Urn Burial de Browne”, Variaciones Borges n 15, enero de 2003, Copenhague, Universidad de Aarhus, p. 19-46.

Borges, Jorge Luis, Obras completas, Buenos Aires, Emecé, 1983.

Brient, Pierrick, “Nullibiété”, Essaim n 18, 2007, Toulouse, Éditions Érès, p. 129-132.

Candlish, Stewart y Wrisley, George, "Private Language", The Stanford Encyclopedia of Philosophy, 2019, Web. Consultado el 14 de diciembre de 2019.

Chesterton, Gilbert Keith, G. F. Watts [1904], Nueva York, Barnes \& Noble, 2011.

Dapía, Silvia G., Jorge Luis Borges, Post-Analytic Philosophy, and Representation, Nueva York, Routledge, 2016.

Freud, Sigmund, Obras completas. XIV (1914-1916), Buenos Aires, Amorrortu, 1992. Traducción de José L. Etcheverry.

Glozman, Mara, Lengua y peronismo. Políticas y saberes lingüísticos en la Argentina, 1943-1956, Buenos Aires, Ediciones Biblioteca Nacional, 2015.

Glozman, Mara y Lauria, Daniela, Voces y ecos. Una antología de los debates sobre la lengua nacional (Argentina, 1900-2000), Buenos Aires, Cabiria/Biblioteca, Nacional, 2012.

Hacking, Ian, Historical Ontology, Cambridge, Londres, Harvard University Press, 2002.

Hegel, Georg Wilhelm Friedrich, Fenomenología del espíritu, Ciudad de México, Fondo de Cultura Económica, 1998. Traducción de Wenceslao Roces.

---, La Raison dans l'histoire, París, Éditions 10/18 (Union générale d'éditions), 1965. Traducción al francés de Kostas Papaioannou.

Hylton, Peter y Kemp, Gary, "Willard Van Orman Quine", The Stanford Encyclopedia of Philosophy, 2019, Web. Consultado el 15 de diciembre de 2019.

Kojève, Alexandre, Introduction à la lecture de Hegel, París, Gallimard, 1968.

---La concepción de la antropología y del ateísmo en Hegel, Buenos Aires, La Pléyade, 1972. Traducción de Juan José Sebreli.

Lacan, Jacques, Escritos I, Ciudad de México, Siglo XXI editores, 1998. Traducción de Tomás Segovia. 
Lamborghini, Osvaldo, Tadeys, Buenos Aires, Sudamericana, 2005.

Nelson, Daniel E., "Un texto proteico: los San Signos de Xul Solar", en Solar, Xul, Los San Signos. Xul Solar y el I Ching, Buenos Aires, El Hilo de Ariadna, 2012.

Penny, Ralph, Gramática histórica del español, Barcelona, Ariel, 1998. Traducción de José Ignacio Pérez Pascual.

Prat, Jean (realizador) y Pierre Dumayet (entrevistador), Jorge Luis Borges [entrevista

televisiva], París, ORTF (Office de radiodiffusion-télévision française), 1964.

Putnam, Hilary, Realism with a Human Face, Cambridge y Londres, Harvard University Press, 1992.

Rest, Jaime, El laberinto del universo. Borges y el pensamiento nominalista, Buenos Aires, Ediciones Librerías Fausto, 1976.

Rosa, Nicolás, La letra argentina, Buenos Aires, Santiago Arcos, 2003.

Russell, Bertrand, Introduction to Mathematical Philosophy, Londres, George Allen \& Unwin, 1920.

---, The Analysis of Mind [1921], Nueva York, Routledge, 1995.

---, The Philosophy of Logical Atomism [1918], Nueva York, Routledge, 2010.

Saussure, Ferdinand de, Curso de lingüística general, Buenos Aires, Losada, 1994. Traducción de Amado Alonso.

Sterne, Laurence, La vida y las opiniones del caballero Tristram Shandy, Barcelona, Alfaguara, 2006. Traducción de Javier Marías.

Verón, Eliseo y Sigal, Silvia, Perón o muerte. Los fundamentos discursivos del fenómeno peronistas, Buenos Aires, Legasa, 1985.

Wittgenstein, Ludwig, Investigaciones filosóficas, Barcelona, Grijalbo, 1988. Edición bilingüe. Traducción de Alfonso García Suárez y Ulises Moulines.

\section{NOTES}

1. Salvo que se indique lo contrario en la Bibliografía, las traducciones son nuestras.

2. “...la filosofía de Kant se funda en la privacidad, tanto como la de Descartes o Locke o Leibniz. Una persona es un ego con una vibrante secuencia de impresiones sensibles y pensamientos. De ahí que surja la necesidad de descubrir una base para la objetividad. [...] La voz de la razón es la voz de la estandarización de las normas públicas. Estas son requeridas por un yo cuya esencia es privada, una esencia cuya objetividad viene dada solo por 'la unidad trascendental de la apercepción', de acuerdo con la cual todo pensamiento viene acompañado por el pensamiento 'yo pienso esto"”. (Hacking 134).

3. El adjetivo empleado por Wittgenstein es denkbar, que bien puede ser "pensable", "concebible". 4. La expresión "ficciones de ficciones" se encuentra en The Philosophy of Logical Atomism: "Numbers are classes of classes, and classes are logical fictions, so that numbers are, as it were, fictions at two removes, fictions of fictions" (2010: 111). La teoría de estas "ficciones" Borges la conocía por haber leído la Introduction to Mathematical Philosophy, libro citado en "La perpetua carrera de Aquiles y la tortuga" (1932) y todo a lo largo del cual Russell emplea la palabra fiction. Por cierto, también aquí se alude a un lenguaje perfecto (Russell 1920: 183).

5. Silvia Dapía, quien emplea la expresión "private language" a propósito de Funes, observa: "since for Funes each of those perspectives merits a unique concept, it is easy to understand why for him even Locke's utopian language would be 'too ambiguous'. Funes is dealing with a 'multiform, 
momentaneous, and almost unbearably precise world,' and even Locke's language would fall short of it" (40). Según nuestro argumento, si el lenguaje imaginado por Russell sigue siendo tan privado como el de Locke, carece, en cambio, del defecto de la ambigüedad y puede dar cuenta tanto de lo momentáneo como del perspectivismo de Funes. A este respecto, cabe recordar que la cuestión de la perspectiva (es decir, el perro "cubista”, casi duchampiano de Funes) juega un rol importante en The Analysis of Mind (por ejemplo, $102 \mathrm{y}$ ss.).

6. Russell, Locke, Quine. A esta genealogía tan anglosajona podría añadirse el uruguayo Ireneo Funes, si creemos los rumores según los cuales "su padre era un médico del saladero, un inglés O'Connor" (486). Aunque el nombre es más bien irlandés, la ascendencia inglesa no debe ser descartada si hemos de creer la afirmación de Borges (en "El ruiseñor de Keats") según la cual los adjetivos "inglés" y "abstracto" se repelen: "El inglés rechaza lo genérico porque siente que lo individual es irreductible, inasimilable e impar. Un escrúpulo ético, no una incapacidad especulativa, le impide traficar en abstracciones" (709).

7. "The suggestion that a language could be private in the way described appears most openly in the second of Bertrand Russell's published lectures 'The Philosophy of Logical Atomism' [...] Although Wittgenstein does not explicitly say so, it is likely that this is the inspiration of his argument: his writing is marked in many places by criticism of Russell, both explicit and otherwise" (Candlish y Wrisley 2019 Web). Pero no olvidemos que, al mismo tiempo, Russell declara, al comienzo de The Philosophy of Logical Atomism, que las ideas que expone le fueron inspiradas por su "antiguo alumno Ludwig Wittgenstein" (Russell 2010: 1). Wittgenstein también es mencionado, esta vez como "my friend", en una nota al pie de The Analysis of Mind (230).

8. Ver, al respecto, Blanco (2003).

9. No sin ciertos matices, ya que, hacia 1830, Hegel habría manifestado algunas tendencias privatistas (Hacking 123-124).

10. Retomamos en este apartado algunas ideas presentadas en Arias (2015, 2016, 2017 y 2018).

11. El narrador-lingüista nos habla de la "superabundancia excremencial y sexual de la lengua de La Comarca, lengua especial para crear una genial literatura popular, desbordante de erotismo y de funciones orgánicas naturales" (376).

12. Otro punto en común es la mezcla etimológica. Compárese la descripción del narradorlingüista de Tadeys citada hace un momento con esta que hace Daniel Nelson del neocriollo: "Como una mezcla de raíces españolas y portuguesas, el neocriollo empezó la vida como un lenguaje artificial a posteriori alrededor del año 1915 [...] Pero también hay que notar la introducción de múltiples raíces basadas en el inglés, el francés, el alemán, el italiano, el latín, el griego antiguo, el hebreo, el tupí-guaraní, el náhuatl, el sánscrito y el chino, y finalmente del lenguaje infantil y de la nomenclatura científica moderna..." (29). Esbozamos una comparación del comarquí y el neocriollo en Arias (2017).

13. En versión de Albertina Carri y Analía Couceyro, la obra fue representada durante 2019 en el Teatro Nacional Cervantes.

14. Hay dos lenguas imaginadas en la novela de Lamborghini: el comarquí y el sistema de ruidos con que se comunican los tadeys.

15. Algunos pasajes borgeanos de Tadeys: "un absoluto que nadie pudiera encontrar siquiera en la Enciclopedia más famosa, falsa o veraz, llena de planetas inventados y de islas habitadas solo por los caballos salvajes -cimarrón" (281); "Hasta que de pronto, en un instante plisado, centrándose en un punto, que giró 'unánime' como la noche que nadie vio desembarcar- quedó tranquilo como a veces quieta el agua" (289); “Por ejemplo, un tal Don, inglés que decía al volver, así nomás el bárbaro de sencillo: Cristo fue un suicida. Nos vendió la comedia y murió (¿cómo puede morir un inmortal?)" (282); las desopilantes reflexiones de Maker sobre su condena en un infierno sueco (¡A Suecia! ¡Viva el comarquí, muera el latín!” (210)) aluden a la versión borgeana de Swedenborg en "Un teólogo en la muerte" (Historia universal de la infamia). Para una comparación 
fundada en las relaciones paradójicas Borges/O. Lamborghini, véase el ensayo de Rosa (2003: 185-217).

16. Transcribimos el fragmento de la biografía del pintor G. F Watts, de Chesterton, de donde provienen las líneas finales (destacadas aquí en itálicas) de "El idioma analítico de John Wilkins": "Every time one man says to another, "Tell us plainly what you mean?" he is assuming the infallibility of language: that is to say, he is assuming that there is a perfect scheme of verbal expression for all the internal moods and meanings of men. Whenever a man says to another, "Prove your case; defend your faith," he is assuming the infallibility of language: that is to say, he is assuming that a man has a word for every reality in earth, or heaven, or hell. He knows that there are in the soul tints more bewildering, more numberless, and more nameless than the colours of an autumn forest; he knows that there are abroad in the world and doing strange and terrible service in it crimes that have never been condemned and virtues that have never been christened. Yet he seriously believes that these things can every one of them, in all their tones and semi-tones, in all their blends and unions, be accurately represented by an arbitrary system of grunts and squeals. He believes that an ordinary civilized stockbroker can really produce out of his own inside noises which denote all the mysteries of memory and all the agonies of desire. Whenever, on the other hand, a man rebels faintly or vaguely against this way of speaking, whenever a man says that he cannot explain what he means, and that he hates argument, that his enemy is misrepresenting him, but he cannot explain how; that man is a true sage, and has seen into the heart of the real nature of language" (Chesterton [1904] 2011: 58-59).

17. La toponimia importa. A este lugar de Buenos Aires (hoy, la Avda. Leandro N. Alem) en que se encuentran las literaturas de Borges, José Bianco y Osvaldo Lamborghini, nos referimos en Arias (2015).

18. En su estudio sobre el peronismo, Verón y Sigal nos proveen una valiosa indicación a propósito de este anudamiento de lo público y lo obsceno. Se trata de la palabra de Perón en el exilio: "La interdicción de la palabra pública del líder, que es la prohibición del acto de enunciación, abre la puerta a una profusión de enunciados y de intermediarios. Este sistema que fue políticamente rentable para el peronismo [...]- es posible mientras se mantenga la invisibilidad de la enunciación, ya que la materialización de ésta no es otra cosa que la presencia física de Perón en el país. Sería difícil explicar de otro modo la conmoción que produce, casi un año después de la elección de Frondizi, el anuncio de la existencia de un pacto firmado entre este y Perón, que, en las palabras de uno de sus protagonistas secundarios, fue considerado '... como si fuera un acto vergonzoso o pornográfico [...]. . En la situación del exilio, toda materialización de la enunciación - presencia de Perón- es vivida como una ruptura de la regla de la invisibilidad, como la visualización ('pornográfica') de algo que debía permanecer oculto" (113).

19. El autor agradece los inteligentes comentarios de Graciela Villanueva, Federico Calle Jordá y Diego Vecchio, quienes tuvieron la amabilidad de leer versiones preliminares de este artículo.

\section{ABSTRACTS}

In this article, we try to consider, from a literary point of view, the two opposite conceptions of language distinguished by epistemologist Ian Hacking under the headings of "private linguists" and "public linguists". The former postulate the existence of a "mental speech" prior to every external manifestation of language. Among them is Bertrand Russell, whose connections with Borges' literature, particularly with one of his imaginary languages, we explore in the first part 
of the article. According to the second conception of language, which is advocated by public linguists, it is absurd to postulate any language as alien to all forms of community. Public linguists can also be found in Borges's fiction, and they allow us to explore points of connection with the imaginary languages of another Argentinian writer: Osvaldo Lamborghini.

En este artículo intentamos considerar, desde un punto de vista literario, las dos concepciones antagónicas del lenguaje distinguidas por el epistemólogo Ian Hacking bajo los rótulos de "lingüistas privados" y "lingüistas públicos". Los primeros postulan la existencia de un "discurso mental" previo a toda manifestación externa de la palabra. Entre ellos se encuentra Bertrand Russell, cuyas conexiones con la literatura de Borges, especialmente con una de sus lenguas imaginarias, exploramos en la primera parte del trabajo. De acuerdo con la segunda concepción del lenguaje, representada por los lingüistas públicos, es absurdo postular cualquier lenguaje ajeno a alguna forma de comunidad. Lingüistas públicos también pueden encontrarse en la ficción de Borges, y permiten explorar puntos de conexión con las lenguas imaginarias de otro escritor argentino: Osvaldo Lamborghini.

Dans cet article nous essayons de considérer, d'un point de vue littéraire, les deux conceptions opposées du langage distinguées par l'épistémologue Ian Hacking sous les rubriques de « linguistes privés » et de « linguistes publics ». Les premiers postulent l'existence d'un « discours mental » préalable à toute manifestation externe de la parole. Parmi eux se trouve Bertrand Russell, dont les connexions avec la littérature de Borges, particulièrement avec une de ses langues imaginaires, nous explorons dans la première partie de l'article. D'après la deuxième conception du langage, représentée par les linguistes publics, il est absurde de postuler un langage étranger à toute forme de communauté. Des linguistes publics se trouvent aussi dans la fiction de Borges, et ils permettent d'explorer des points de connexion avec les langues imaginaires d'un autre écrivain argentin : Osvaldo Lamborghini.

\section{INDEX}

Mots-clés: linguistes publics, linguistes privés, langage logiquement parfait, comarqui, langues imaginables

Palabras claves: lingüistas públicos, lingüistas privados, lenguaje lógicamente perfecto, comarquí, lenguas imaginables

Keywords: public linguists, private linguists, logically perfect language, comarqui, imaginable languages

\section{AUTHOR}

\section{MARTÍN ARIAS}

Université Paris 8

martin.arias-pini02@univ-paris8.fr 